\title{
CORRELAÇÃO ENTRE OS TEORES DE LÍBER E FIBRAS EM CAULES DE CROTALÁRIA E MALVA (')
}

\author{
ANISIO AZZINI $(2,5)$, DIRCEU CIARAMELLO $\left({ }^{2}\right)$, \\ ANTÔNIO LUIZ DE BARROS SALGADO (2), CRISTINE CLAUSSE (2, 3) \\ e MARIA CARLA QUEIROZ DE ARRUDA $(2,4)$
}

\begin{abstract}
RESUMO
No presente estudo, estimou-se a correlação entre os teores de líber (casca) e fibras em caules de crotalária (Crotalaria juncea L.) e malva (Urena lobata L.), com o objetivo de estabelecer um procedimento simples e rápido de análise de fibra. Os resultados obtidos mostraram que os teores de líber e fibra estão relacionados entre si, com alto nível de significância ( $p>0,99)$ para as correlaçoes entre essas duas características tecnológicas. Os coeficientes de correlação observados, de 0,84 e 0,79 , respectivamente, para crotalária e malva, permitem a avaliação indireta do teor de fibra liberiana através do teor de líber, estabelecendo um procedimento simples e rápido de análise de fibra, a ser utilizado especificamente em programas de melhoramento genético.
\end{abstract}

Termos de indexação: Crotalaria juncea L.; Urena lobata L.; fibras liberianas; anălise tecnologica.

(1) Recebido para publicaçāo em 6 de novembro de 1985.

(2) Seçāo de Plantas Fibrosas, Instituto Agronómico (IAC), Caixa Postal 28, 13001 Campinas (SP).

(3) Estagiária, estudante do Curso de Agronomia Tropical do Instituto Superior de Técnicas do Ultra-Mar - Havre - França.

(4) Química Tecn6loga. Bolsista da FAPESP.

(5) Com bolsa de suplementaçāo do CNPq. 


\section{INTRODUÇÃO}

As principais utilizações das folhas liberianas de crotalária (Crotalaria juncea L.) e malva (Urena lobata L.) têm sido, respectivamente, na produção de papéis para cigarro e na manufatura de sacaria para café e cereais. Além da produção de fibras celulósicas para papel, o cultivo da crotalária tem sido utilizado para melhorar as características físicas, quimicas e biológicas dos solos, aproveitando o grande potencial da sua fitomassa como adubo verde.

Os niveis de produção de fibras liberianas variam de 0,6 a 1,5 tha para malva (ALBUQUERQUE \& SOARES, 1968) e de 2,5 a 3,5 tha para crotalária (SALGADO et alii, 1980). Esses niveis podem ser aumentados através do melhoramento genético das plantas; observou-se em pesquisas na Seção de Plantas Fibrosas do Instituto Agronômico grande variabilidade nos teores de fibras liberianas, tanto em crotalária como em malva. A metodologia para a determinação dessas fibras é morosa e exige uma deslignificação química das amostras para a individualização das fibras celulósicas. Para agilizar o processo de seleção das plantas, estimou-se a correlação entre os teores de líber (casca) e fibra em caules de crotalária e malva, com o objetivo de estabelecer um procedimento simples e rápido de análise de fibra.

\section{MATERIAL E MÉTODOS}

Caules de crotalária e malva, com quatro e oito meses de idade respectivamente, foram colhidos no Centro Experimental de Campinas em ensaios conduzidos pelas Seções de Leguminosas e Plantas Fibrosas do Instituto Agronômico. Para cada espécie, colheram-se ao acaso 50 plantas, determinando-se seus diâmetros e os pesos dos caules com e sem folhas. As amostras para as determinaçōes dos teores de líber e fibra foram obtidas no terço médio do caule de cada planta. O teor de liber foi calculado pela relação porcentual entre o peso do líber e $o$ do caule, ambos secos em estufa a $105 \pm 3^{\circ} \mathrm{C}$. As fibras liberianas foram obtidas após a deslignificação das amostras do líber em solução de hidróxido de sódio a $5 \%(\mathrm{~m} / \mathrm{v})$, durante duas horas a uma temperatura de $70^{\circ} \mathrm{C}$. A relação porcentual entre os pesos secos da fibra e do caule forneceu o teor de fibras liberianas.

\section{RESULTADOS E DISCUSSÃO}

As características tecnológicas dos caules de crotalária e malva, com relação a altura e diâmetro das plantas, peso e teores de caule, ramos, líber e fibras encontram-se no quadro 1 . Os dados obtidos revelaram nítida superioridade dos caules de malva quanto ao rendimento de fibras liberianas. O menor desenvolvimento das plantas de crotalária foi influenciado pelo plantio tardio, efetuado 
em meados de abril de 1985. Em condições normais de plantio para a produção de fibras, as plantas de crotalária atingem 2-3 $\mathrm{m}$ de altura, com diâmetro basal dos caules de $1 \mathrm{~cm}$. Por ser matéria-prima tradicionalmente utilizada na produção de papéis para cigarro, a crotalária tem sido submetida a um contínuo processo de melhoramento genético, apresentando, por essa razão, em relação à malva, maior porcentagem de caule e, conseqüentemente, menor quantidade de ramos $\mathrm{e}$ folhas, indesejáveis no aproveitamento industrial das fibras liberianas.

Os teores de líber e fibra nos caules de crotalária e malva estão relacionados entre si, com alto nivel de significância $(p>0,99)$ para as correlaçōes entre essas duas características tecnológicas. Os coeficientes de correlação observados foram de 0,84 e 0,79, respectivamente, para crotalária e malva. Esses niveis de correlação permitem que os teores de fibras liberianas nos caules sejam avaliados indiretamente pelos teores de líber ou casca, cuja determinação é de execução simples e rápida. Esse procedimento de análise indireta de fibra pode ser empregado especificamente para a seleção de plantas em programas de melhoramento genético de crotalária e malva, onde há necessidade de avaliar grande número de plantas.

QUADRO 1. Características tecnologicas dos caules de crotalária e malva. Médias de 50 repetiçōes

\begin{tabular}{|c|c|c|}
\hline Características tecnológicas & Crotalária & Malva \\
\hline Altura, $\mathrm{cm} \ldots \ldots \ldots \ldots \ldots \ldots \ldots \ldots \ldots$ & 136 & 260 \\
\hline Diâmetro, $\mathrm{cm} \ldots \ldots \ldots \ldots \ldots \ldots \ldots \ldots$ & 0,79 & 1,18 \\
\hline Caules com folhas, $g \ldots \ldots \ldots \ldots \ldots \ldots \ldots \ldots$ & 67,8 & 275,8 \\
\hline Caules sem folhas, $g \ldots \ldots \ldots \ldots \ldots \ldots \ldots \ldots$ & 57,4 & 198 \\
\hline Teor de caule, $\% \ldots \ldots \ldots \ldots \ldots \ldots \ldots \ldots$ & 84,6 & 71,8 \\
\hline Teor de ramos com folhas, $\% \ldots \ldots \ldots \ldots \ldots$ & 15,4 & 28,2 \\
\hline Teor de liber, $\% \ldots \ldots \ldots \ldots \ldots \ldots \ldots \ldots$ & 15,5 & 25,9 \\
\hline Teor de fibra, $\% \ldots \ldots \ldots \ldots \ldots \ldots \ldots \ldots \ldots$ & 8,5 & 12,5 \\
\hline
\end{tabular}

\section{SUMMARY}

\section{CORRELATION BETWEEN BAST AND FIBER CONTENT IN SUNN HEMP AND MALVA STALKS}

In this paper it was estimated the correlation between the bast and fiber contents in sunn hemp (Crotalaria juncea L.) and malva (Urena lobata L.) stalks. The results showed that fiber contents are related with a high level 
of signification $(p>0.99)$ for the correlation between these two technological characteristics. The correlation coefficients observed were of 0.84 and 0.79 , respectively to sunn hemp and malva. These high levels of correlation showed that the fiber content may be evaluated indirectly through the bast content, establishing a simple and rapid procedure for fiber determination of both species.

Index terms: sunn hemp, Crotalaria juncea L., malva, Urena lobata L., bast fiber, technological analysis.

\section{REFERÊNCIAS BIBLIOGRÁFICAS}

ALBUQUERQUE, C.R.A. \& SOARES, F. de A.V. Malva. Belém, Instituto de Pesquisa e Experimentaçāo Agropecuária do Norte, 1968. 27p. (Circular, 13)

SALGADO, A.L.B.; AZZINI, A.; PIMENTEL, J.M. \& POTASCHEFF JR., J. Instruções para a cultura da Crotalaria juncea. 2.ed. Campinas, Instituto Agronômico, 1980. 26p. (Boletim, 198) 